\title{
A FRONTEIRA ENTRE A COMUNIDADE E A UNIDADE DE CONSERVAÇÃO MASTIGADA PELA FORMIGA-ONÇA
}

\author{
Rafael Nogueira Costa $^{1}$ \\ Fátima Branquinho
}

Nesta série de fotos apresentamos um professor de artes acompanhado de seis crianças de uma comunidade periférica de Macaé/RJ à procura dos animais da restinga para serem desenhados em uma prancheta de papel, lembrando os naturalistas e ilustradores científicos dos séculos passados como Maria Sibylla Merian, Alfred Russel Wallace, Alexander von Humboldt e William Henry Edwards.

O cenário para esta "aventura" é o Parque Nacional da Restinga de Jurubatiba, uma unidade de conservação federal, criada em 1998, que protege 44 quilômetros de costa e uma área total de 14.922 hectares, abrangendo os municípios de Macaé, Carapebus e Quissamã no norte do Estado do Rio de Janeiro (Esteves, 2011).

No extremo sul do parque encontra-se uma das maiores comunidades de Macaé, o Bairro Lagomar, classificado pela prefeitura como "assentamento precário" (Macaé, 2012). A expansão do Lagomar acompanhou a intensa movimentação da atividade de exploração de petróleo na região, gerando um crescimento populacional de mais de $400 \%$ em 10 anos a partir do ano 2000, concentrando aproximadamente 50.000 moradores (Correa, 2012).

Apesar desse crescimento populacional o bairro ainda sofre com ausência de saneamento básico (Cuzzatti et al., 2011; Cordeiro et al., 2012) e lidera o índice de domicílios por assentamento precário na cidade (Correa, 2012).

É nesse bairro que mora há mais de vinte anos o professor Ilzimar Bandeira Rodrigues, conhecido como IBR. Além das aulas de artes, IBR é produtor amador de filmes de ficção, desenvolvendo parte da sua criação com as crianças da comunidade.

O personagem principal desta série de fotos não é o parque, nem o professor IBR, nem mesmo as crianças da comunidade, mas sim, um animal de pequeno porte, conhecido vulgarmente como formiga-onça: estamos interessados em observar o que e quem ela é capaz de agenciar ao percorrer a trilha documentada nessas fotos.

\footnotetext{
${ }^{1}$ Universidade Federal do Rio de Janeiro, Brasil.

2 Universidade do Estado do Rio de Janeiro, Brasil.
} 
A analogia da formiga-onça com a teoria descrita por Bruno Latour e colaboradores - ANT (Actor-Network-Theory), formiga em inglês - não é uma simples coincidência neste trabalho. Seguindo a trilha deixada pela formiga apresentada em Latour (2012), aceitamos o convite que este autor nos faz na referida obra, para descrever as transformações na realidade provocadas pelos atores que escolhemos observar: tipologias que produzem, padrões que elaboram, suas máquinas, modo de organização, ideologias, estados de espírito, entre outros.

Formiga-onça ${ }^{3}$ é o nome popular dos insetos do gênero Traumatomutilla sp. Com hábitos solitários, as larvas destes animais são ectoparasitoides de pupas de outros insetos (Bartholomay et al., 2015). As fêmeas adultas são reconhecidas pela coloração chamativa e ausência de asas, apresentando forte dimorfismo sexual, geralmente o macho é alado (Cunha, 2004; Bartholomay et al., 2015). A ausência de asas na fêmea foi suficiente para causar essa "confusão" na identificação do animal, pois para os cientistas da natureza, este pequeno animal não é identificado como formiga, devido suas características peculiares.

A nossa formiga-onça agiu como mediadora ${ }^{4}$ e a sua busca foi marcada pelo rompimento com a fronteira institucional entre a conservação da natureza, na qual o Instituto Chico Mendes de Conservação da Biodiversidade (ICMBio) ocupa posição central desde 2007, e a comunidade do Lagomar, vizinha ao parque, por isso temida e ameaçada.

O arame farpado é a representação da dicotomia natureza/sociedade. Esse ser muito pequeno que transita entre esses universos foi capaz de "mastigar" o arame farpado que separa a comunidade do parque, iniciando o movimento de diluição da fronteira representativa.

Com essas fotos estamos interessados em mostrar que essa separação é mais imaginária do que real. Somos acompanhados pelas minúsculas passadas da "formiga", que foi capaz de aglomerar os humanos e sustentar a produção de uma obra cinematográfica.

\footnotetext{
${ }^{3}$ Também conhecida como formiga-feiticeira, bunda-de-ouro, chiadeira, tajipucu, formiga-ferro, formigas de veludo, entre outros variações dependendo da região.

${ }^{4}$ Para Latour os mediadores "transformam, traduzem, distorcem e modificam o significado ou os elementos que supostamente se veiculam” (Latour, 2012: 65).
} 
As fotos, apresentadas neste relato, compõem o registro da elaboração do filme Um dia novinho em folha ${ }^{5}$, produzido durante o Curso de Cinema Ambiental da Universidade Federal do Rio de Janeiro, em Macaé, no ano de 2013. Foi na produção do filme que observamos a formiga beber água nas mãos do professor IBR.

A construção deste relato audiovisual foi marcada por um diálogo freireano entre a equipe, o IBR e as crianças do Lagomar. Os papeis do diretor de cinema ${ }^{6}$ e do professor do curso foram diluídos para dar entrada a uma construção coletiva e em diálogo circular (Freire, 2013), com reflexos no roteiro, nas escolhas dos enquadramentos e na montagem do filme.

No momento da filmagem no qual buscávamos a formiga-onça, não encontramos o nosso principal personagem. Ensaiamos e representamos um suposto encontro da "formiga" por uma criança, que aos gritos anunciou: "Professor, pra você! Achei a formiga-onça. Professor, corre (...) é ela mesmo". Ficamos diante de uma nova fronteira, o real e a ficção. Inspirados por Jean Rouch, não hesitamos em “perder o pé” e inventamos uma nova realidade (Gonçalves, 2008).

Finalizamos as filmagens com um problema a ser resolvido. Como iríamos inserir as imagens da formiga naquele trecho do filme? O IBR resolveu continuar a busca e comentou com as crianças do bairro que aquele que achasse a formiga-onça, viva, iria receber uma recompensa de dez reais. Dois dias depois recebemos a ligação. "Estou com a formiga-onça esperando para ser filmada".

Imediatamente, pegamos uma Canon 60D, um microfone direcional e fomos até a residência do professor. Rompemos novamente a fronteira para filmar o IBR registrando em sua prancheta o desenho da formiga, imagem que foi posteriormente inserida na montagem do filme.

Outras crianças da comunidade, curiosas pela nossa movimentação, se aproximaram, repetindo aquele encontro maravilhoso que este animal proporcionou: o arame farpado quase rasgando a pele, o parque, as crianças, o sabiá-da-praia, a libélula, os cupins, o vento soprando do leste, o calor da areia, o gasoduto da Petrobras conduzindo $80 \%$ do gás nacional sob os nossos pés, a barraca de praia protegendo do sol escaldante, a garrafa de água gelada, os equipamentos eletrônicos para os registros, a formiga-onça saindo do quadro para continuar a sua jornada solitária.

\footnotetext{
${ }^{5} \mathrm{O}$ registro audiovisual está disponível para visualização em: www.cuca.bio.br

${ }^{6}$ A nossa filiação a esse modo de fazer cinema passa pela capacidade de transformação da realidade pelos participantes envolvidos, mais do que pelo caráter de intervenção supostamente atribuído a ele.
} 
Estávamos, novamente, ali, prontos para sermos dispersos, pois, como defende Latour (2012: 49) "não há grupos, apenas formação de grupos". Mas, afinal, que sentido esse lema da ANT traz para o presente relato? Ele reitera a importância, para a produção do conhecimento sobre a realidade, do registro dos processos, do intercâmbio de papéis, das ações, do movimento, durante a elaboração coletiva do filme que põe em dúvida as fronteiras entre a comunidade, a unidade de conservação, o diretor do filme, o professor do curso, as crianças, as outras crianças, a formiga-onça.
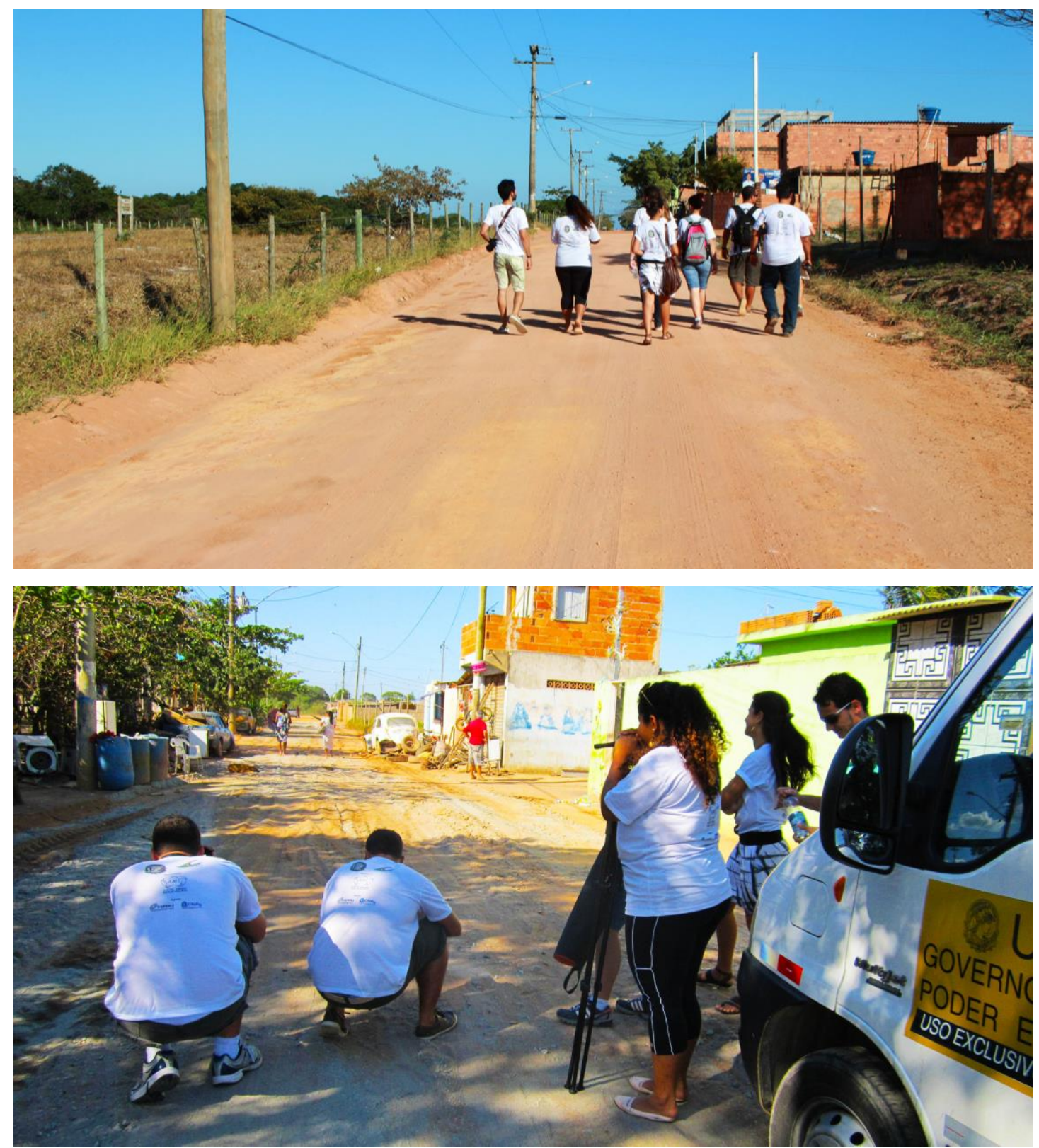

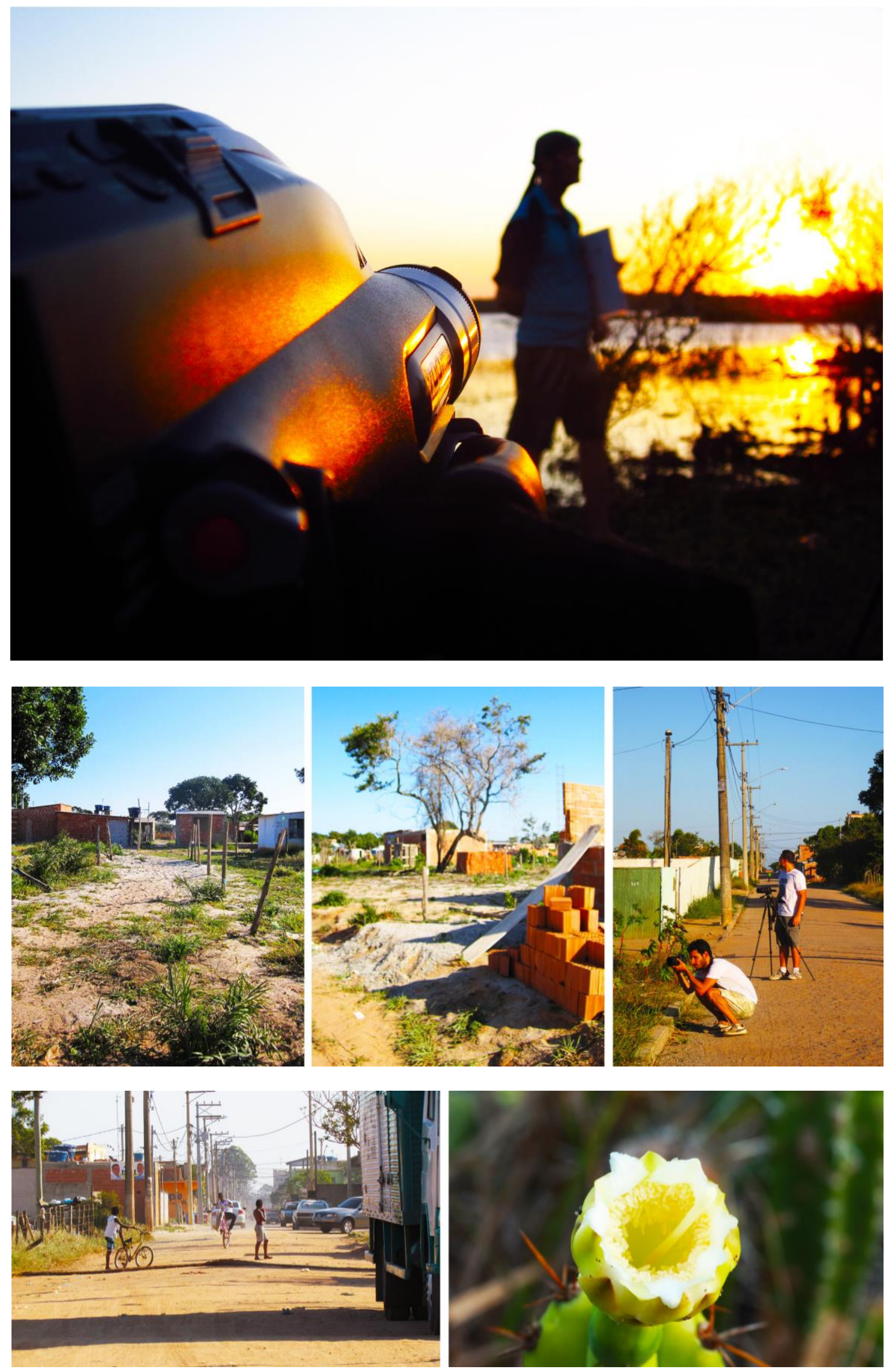

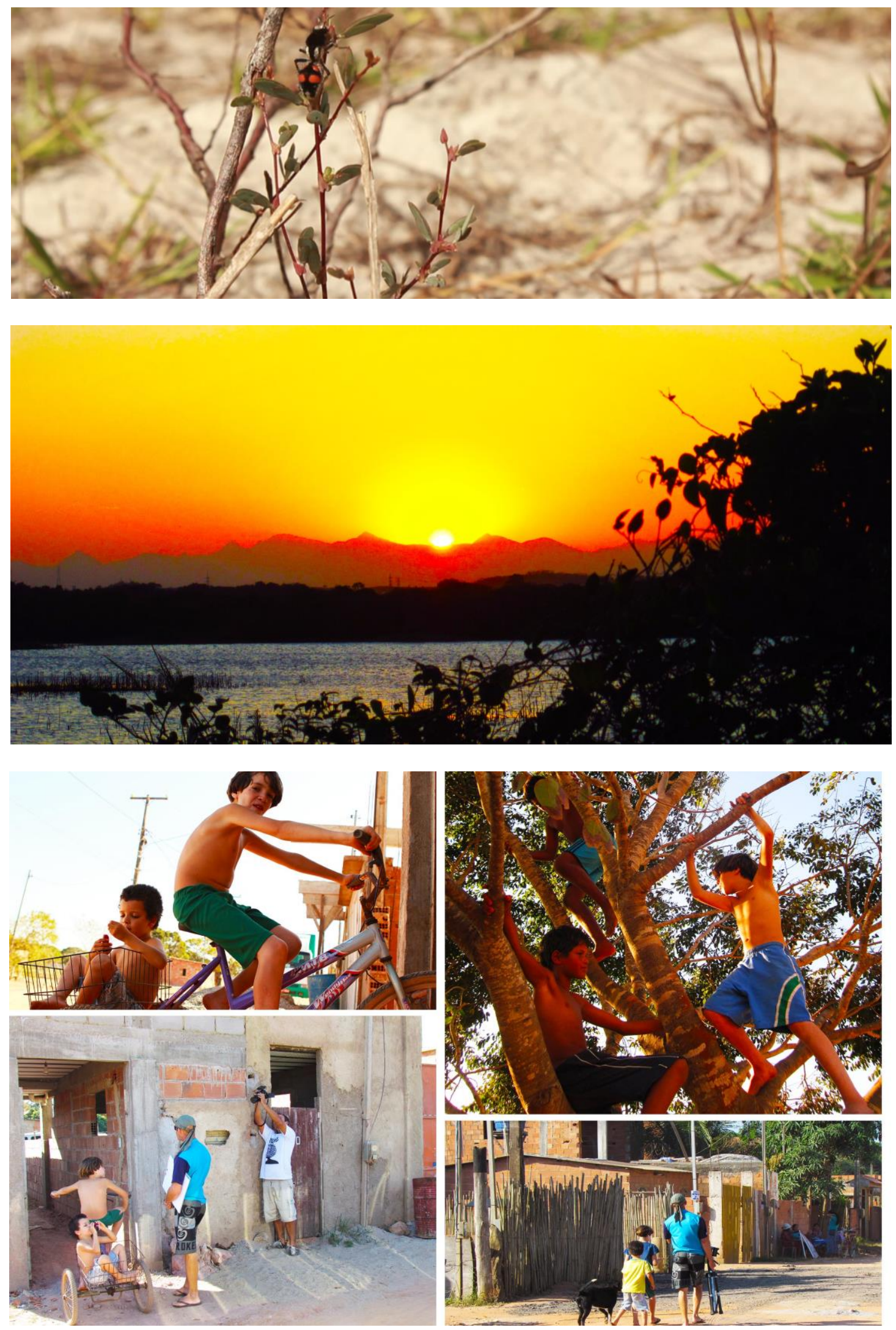

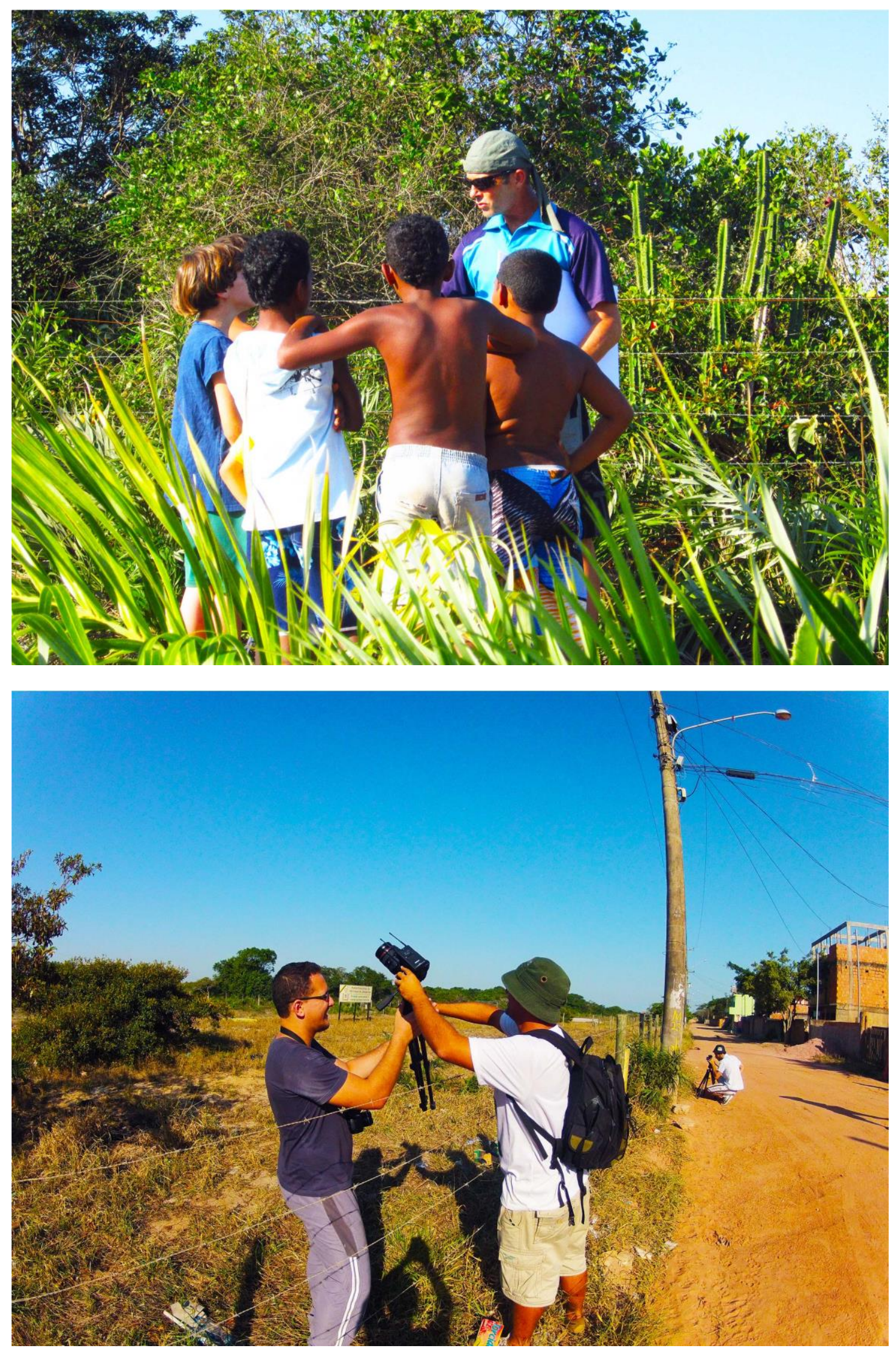

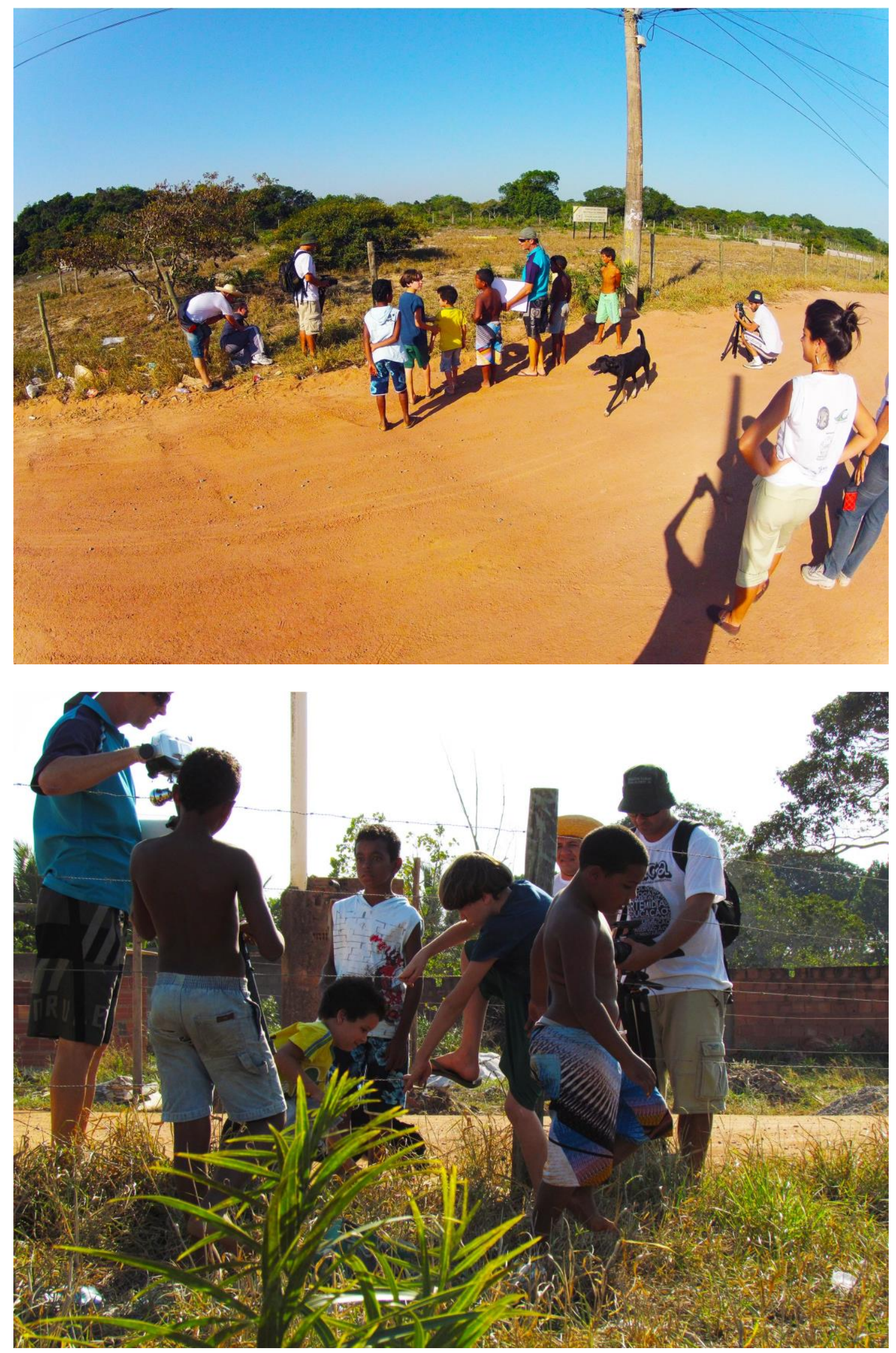

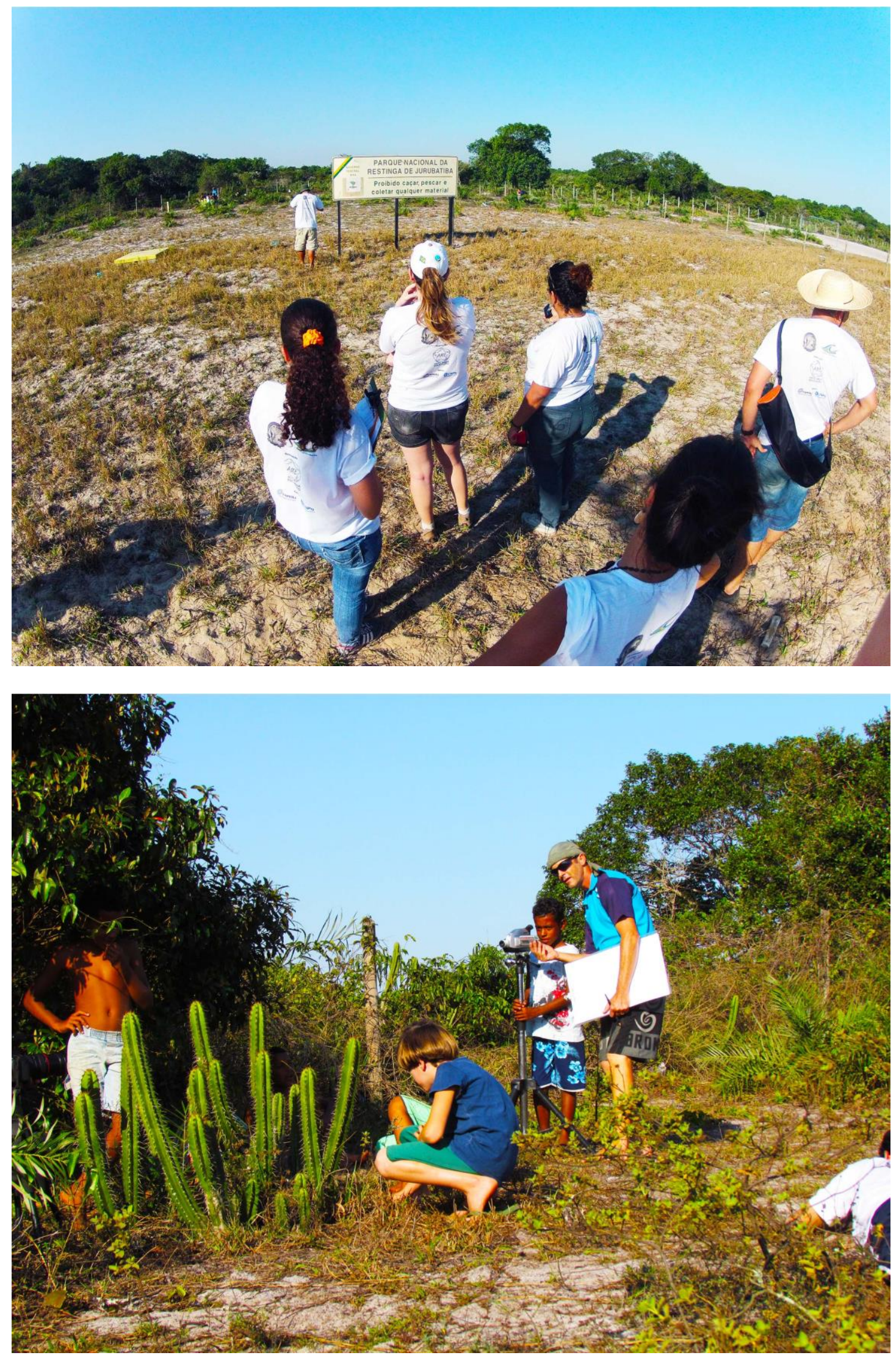

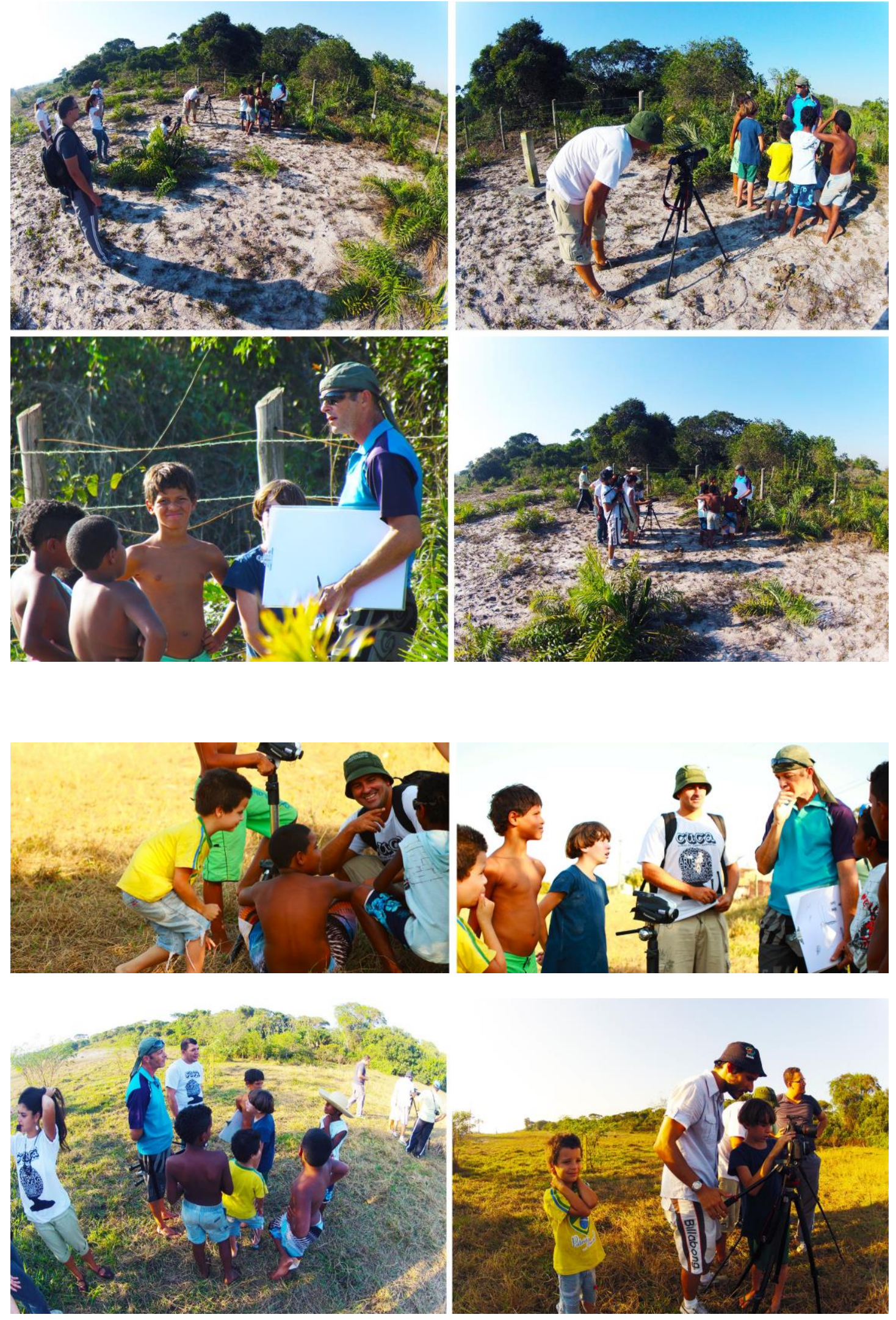

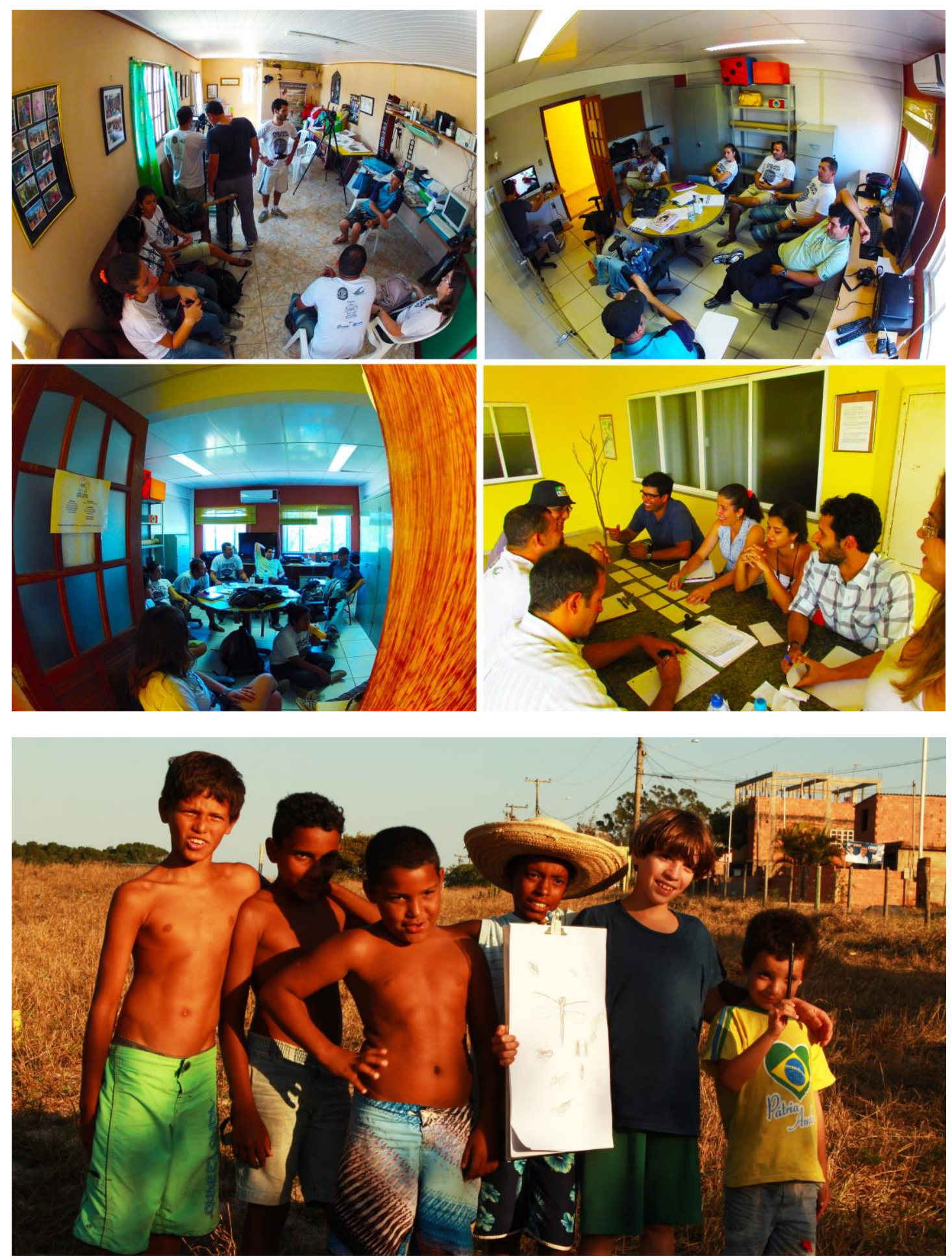

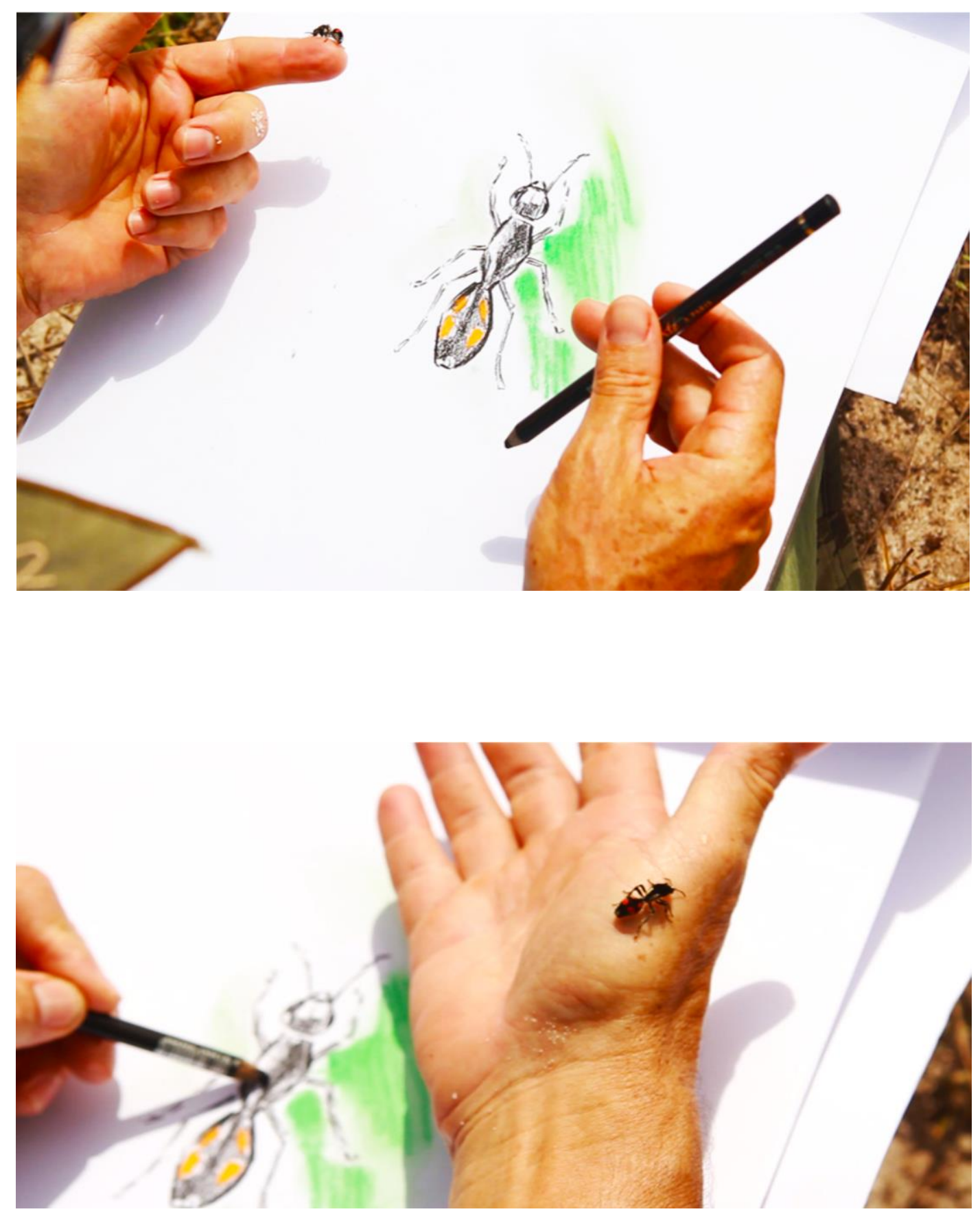

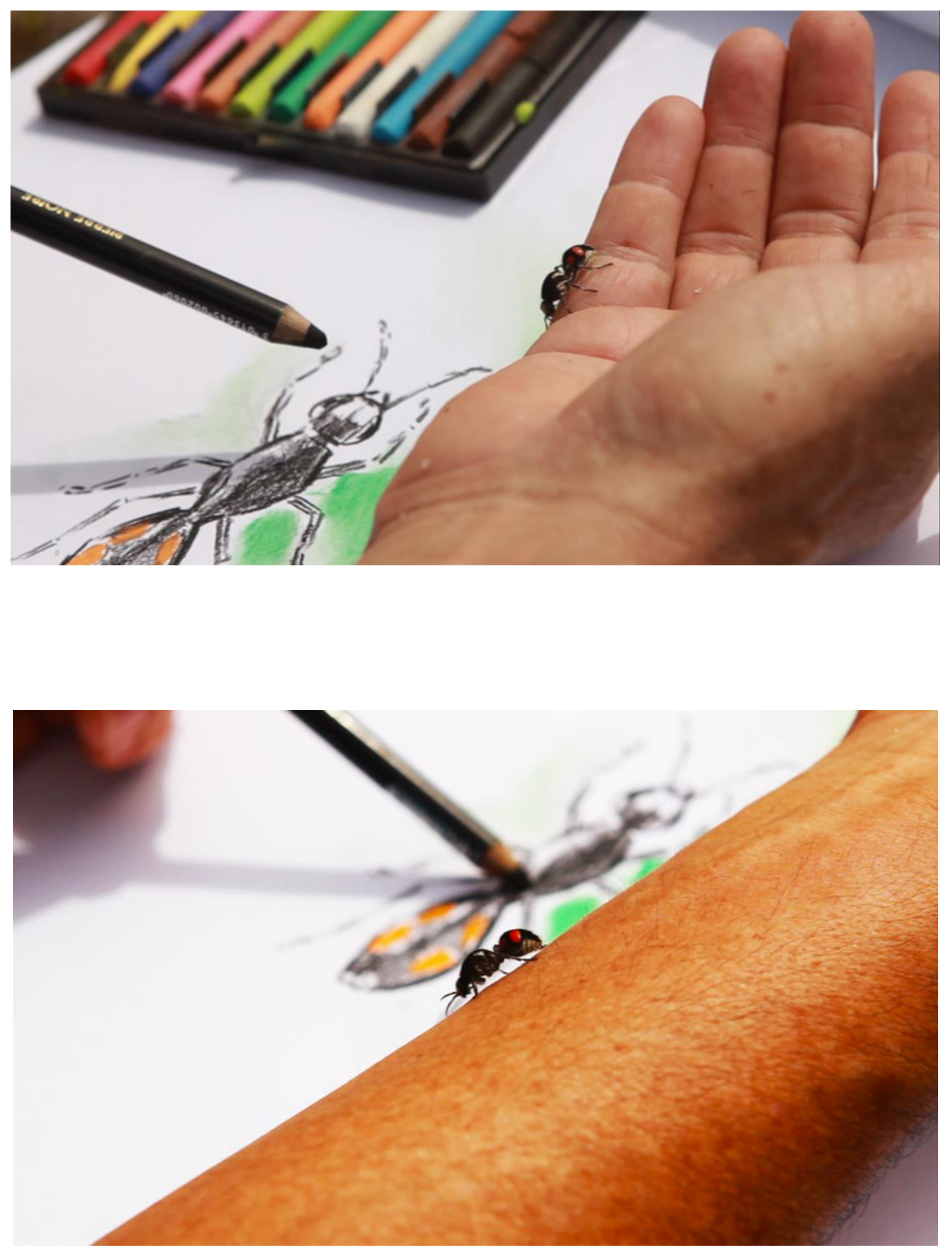

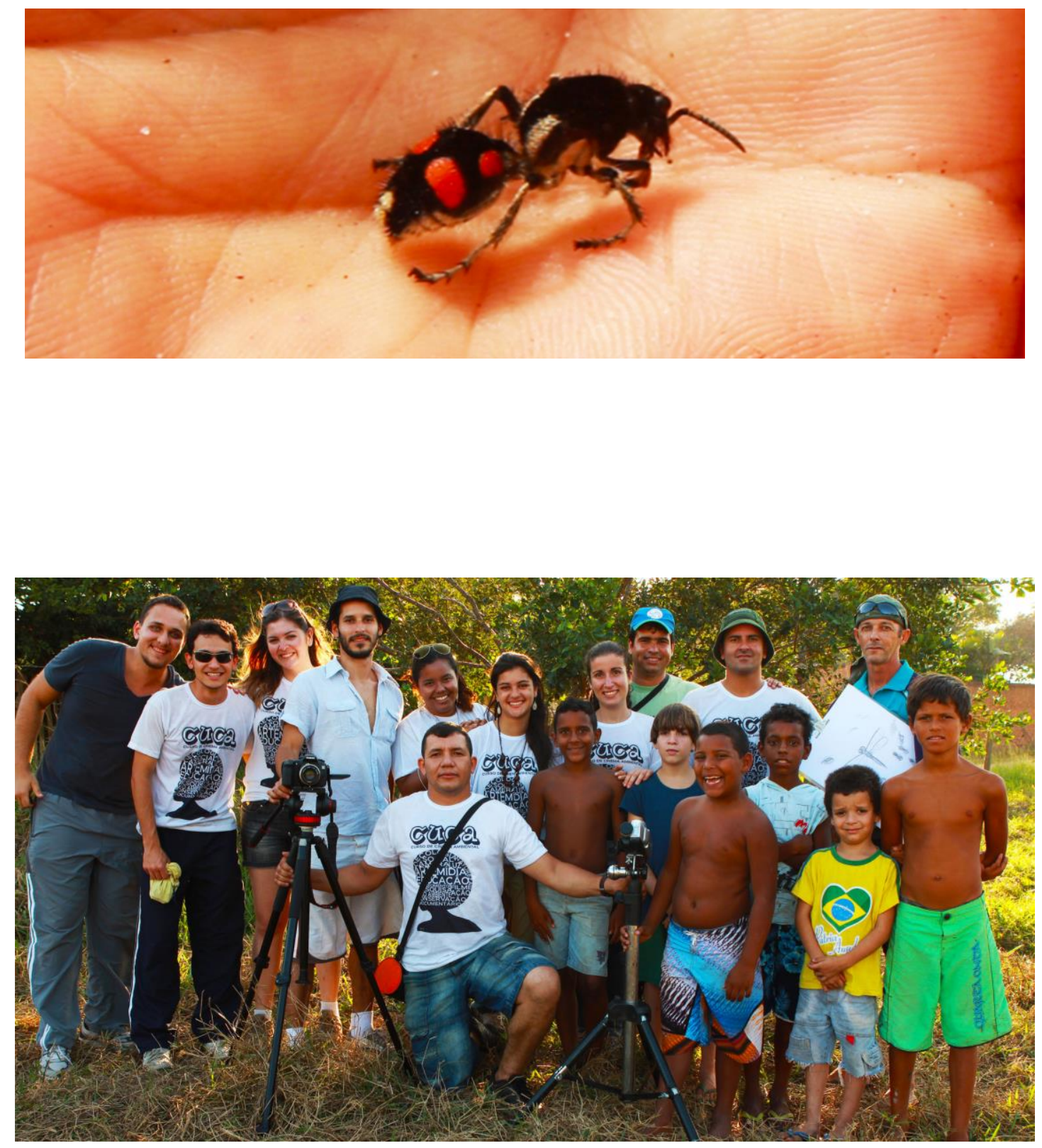
um dir novinho em fohn
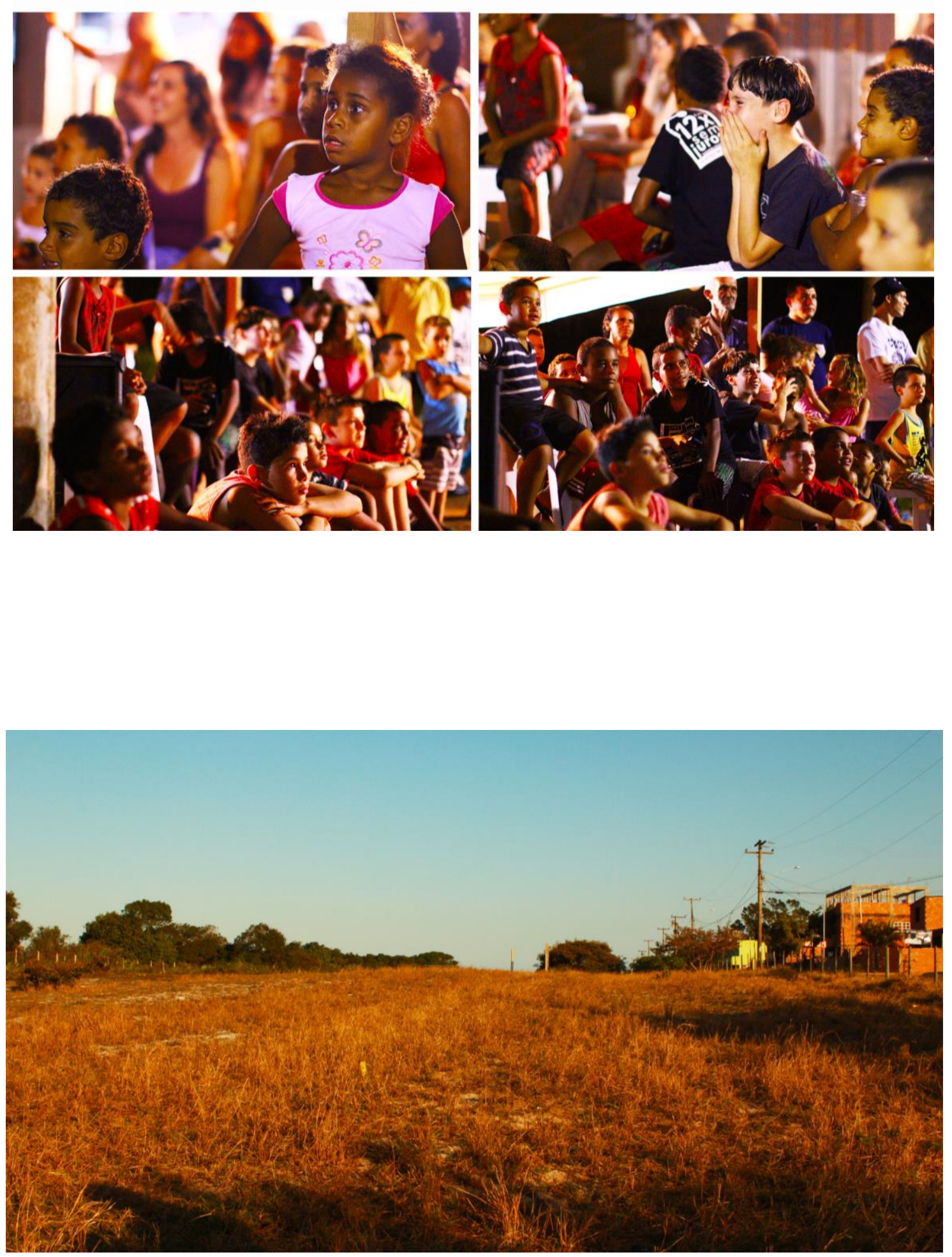


\section{Referências}

BARTHOLOMAY, P.R.; WILLIAMS, K.A.; WALDREN, G.C.; DE OLIVEIRA, M.L. Corrections on the biology of Traumatomutilla André, Hymenoptera: Mutillidae, Zootaxa, 2015. Feb 19; 3920 (1): 198-200. 1901.

CORDEIRO, M.R.; RODRIGUES, S.M.; SOUZA, P.R.N.; FERREIRA, M.I.P. Gestão de Efluentes Domésticos. Fossa Séptica. Contaminação de Águas Subterrâneas. Restinga de Jurubatiba. Publicado In: Boletim do Observatório Ambiental Alberto Ribeiro Lamego, Abril, 2012. Vol.5(1), p. 89-102.

CORREA, R.M. Diagnóstico e plano municipal de prevenção à violência e criminalidade do município de Macaé. $1^{a}$ ed. Prática e Saberes, v.3. Rio de Janeiro: Viva Rio, 2012, p. 272.

CUNHA, R. Monoeca xanthopyga, Hymenoptera, Apoidea, Tapinotaspidini, primeiro registro de hospedeiro para parasitóide do gênero Traumatomutilla, Hymenoptera: Mutillidae, na Serra Geral do Rio Grande do Sul, Brasil. Acta Scientiae, v. 6, n. 2, jul./dez. 2004.

CUZZATTI, T.G.; MARQUES, E.D.; TUBBS, D. Avaliação preliminar da vulnerabilidade na unidade Aquífera do Bairro Lagomar, Macaé-RJ. XII Congresso Brasileiro de Geoquímica. Gramado-RS, 2011.

ESTEVES, F.A. Do índio goitacá à economia do petróleo: uma viagem pela história e ecologia da maior restinga protegida do Brasil. Campos dos Goytacazes, RJ. Essentia Editora, 2011, p. 232.

FREIRE, P. Pedagogia do Oprimido. 54 ${ }^{\mathrm{a}}$ Ed. Rio de Janeiro: Paz e Terra, 2013.

GONÇALVES, Marco Antonio. O real imaginado: etnografia, cinema e surrealismo em Jean Rouch. Rio de Janeiro: Topbooks, p. 239, 2008.

LATOUR, B. Reagregando o social: uma introdução à teoria do ator-rede. Salvador: EDUFBAEdusc, 2012, p. 400.

MACAÉ. Anuário de Macaé 2012. Coordenadoria Geral do Programa Macaé Cidadão. Prefeitura Municipal de Macaé, 2012, p. 538.

Recebido em: 24/04/2016.

Aprovado em: 06/12/2016. 